\title{
ANÁLISE RETÓRICA DAS CAMPANHAS SOBRE HIV/AIDS NO BRASIL E EM OUTROS PAÍSES
}

\section{RHETORICAL ANALYSIS OF CAMPAIGNS ON HIV/AIDS IN BRAZIL AND IN OTHER COUNTRIES}

\author{
Marcelo Leandro Garcia, Marta Bellini e Regina Maria Pavanello \\ Universidade Estadual de Maringá
}

\begin{abstract}
RESUMO
Este artigo tem como objetivo apresentar a analise retórica de 12 imagens de campanhas preventivas da HIV/Aids divulgadas no Brasil, França, Portugal, Argentina e Estado Unidos no período de 2000 a 2006. Das 12 imagens, 4 são francesas, 4 brasileiras, 1 argentina, 2 provenientes dos Estados Unidos e 1 de Portugal. Em um primeiro momento foram observadas as particularidades das figuras e destacados: a) local em que a campanha foi produzida; b) data ou período de divulgação; c) origem: governamental, não governamental ou privada. Em seguida passamos à análise retórica dessas figuras para a qual adotamos, metodologicamente, a abordagem qualitativa fundamentada em Bauer e Gaskell (2005). Pode-se observar que as campanhas francesas de 2004 e 2005, a argentina de 2005 e as americanas de 2003 e 2005 circulam sentidos de terror à síndrome e sua prevenção. As campanhas brasileiras apresentadas em 2001 e 2002 optaram por outros recursos retóricos e sugerem alternativas mais agradáveis e mais informativas. É nítida nas campanhas brasileiras a superação de preconceitos em relação à homossexualidade, ao negro e mesmo de questões religiosas marcantes na cultura do povo brasileiro.
\end{abstract}

Palavras-chave: Aids, Campanhas, figuras de retórica, prevenção.

\begin{abstract}
ABSTRATCT
This article aims to present a rhetorical analysis of 12 images of HIV/AIDS preventive campaigns released in Brazil, France, Portugal, Argentina and the United States from 2000 to 2006. Of these 12 images, four were Brazilian, four French, two from the United Sates, one from Argentina and 1 from Portugal. At first we observed the peculiarities of the figures and noted: a) the place where the campaign was produced, $b$ ) data or reporting period, c) source: governmental, non-governmental or private. Then we moved to the rhetorical analysis of these figures foe which we adopted, methodologically, a qualitative approach based on Bauer and Gaskell (2005). It was observed that in the French campaigns of 2004 and 2005, the Argentinean of 2005 and the ones released in USA in 2003 and 2005 circulated senses of terror to the syndrome and its prevention. The Brazilian campaigns of 2001 and 2002 have opted for other devices suggesting more enjoyable and informative alternatives and overcoming prejudices about homosexuality, ethnicity, as well as religious issues that are outstanding in the Brazilian culture.
\end{abstract}

Key-Words: SIDA, Campaigns, Rhetorical Words, Prevention. 


\section{INTRODUÇÃO: as campanhas de prevenção ao HIV/Aids}

Para compor uma discussão sobre a circulação dos sentidos de imagens das campanhas de prevenção sobre HIV/Aids analisamos 12 imagens produzidas no Brasil (4), França (4), Portugal (1), Argentina (1) e Estados Unidos (2). Destacamos: a) local em que a campanha foi produzida; b) data ou período de divulgação; c) origem: governamental, não governamental ou privada e examinamos o alcance e os sentidos produzidos pelas figuras de retórica.

Sabemos não existir ainda, no caso específico do HIV/Aids, a cura, mas os efeitos dessa síndrome podem ser amenizados pelas terapias retrovirais. Todavia, o modo mais eficaz de controle do HIV/ Aids é a sua prevenção. Assim, quando o objetivo é a prevenção, os estudos sobre HIV/Aids não podem ignorar a educação.

Ayres (2002) trata desse tema. Para o autor as primeiras campanhas sobre a prevenção do HIV/Aids foram estruturadas e fundamentadas em mensagens textuais e por imagens que inspiravam sentimentos de medo e terror. Elaboradas dessa maneira, ao invés de colaborarem para a prevenção, elas criaram problemas para a compreensão da sexualidade e de modos de prevenção adequados. Em virtude disso, estas campanhas sobre o HIV/Aids desinformaram mais do que educaram (AYRES, 2002).

Se os principais problemas enfrentados pelos grupos que trabalham na prevenção do HIV/Aids são o preconceito e a discriminação, era preciso garantir contextos culturais para as campanhas. Era necessário lançar mão de teorias da comunicação para provocar o entendimento das estratégias do controle do vírus. Neste sentido, Ayres (2005, p. 4) argumenta que:

\footnotetext{
É preciso explorar as boas qualidades da grande mídia e tentar trabalhar em nível local aspectos em que as mensagens veiculadas possam trazer prejuízos, como a disseminação de estigmas, a inteligibilidade de algumas mensagens que podem criar mais confusão que esclarecimento, a estimulação de atitudes massificadoras, dogmáticas, contrárias ao pluralismo e às construções dialógicas de respostas à epidemia.
}

As primeiras campanhas de prevenção ao HIV/Aids estabeleceram a ligação entre a sexualidade e a morte. Tratou-se a síndrome como "doença" de pessoas com “comportamento de risco". Nessa fase, Giami (1997) destaca o papel da metáfora no 
discurso de prevenção que vincula a síndrome à "punição divina" ou "castigo". A caracterização da epidemia como erro ou castigo, que existiu tanto nas sociedades antigas como nas contemporâneas, traz a marca da culpa dos indivíduos, o que retira o problema da esfera coletiva e pública. Além disso, cria o vínculo entre sexo e afetividade com morte por erro.

Felizmente, desde 1985, a Síndrome da Imunodeficiência Adquirida não está mais circunscrita aos hemofílicos, usuários de drogas injetáveis e homossexuais. $\mathrm{O}$ HIV/Aids pode atingir, indistintamente, não só a esses grupos, mas também a bissexuais e heterossexuais, adultos ou crianças (GIAMI, 1997 p. 68). Entretanto, mesmo com o padrão epidemiológico mudado, ainda hoje se paga o "tributo à dicotomia" visto que consideramos o HIV/Aids uma doença do "outro" - do homossexual ou usuário de drogas injetáveis, da esposa fiel e ingênua que não exige do marido o uso de preservativo (PIMENTA, apud EPSTEIN, 2001, p. 843).

Embora em 1985 os médicos já não ligassem o HIV/Aids aos grupos de comportamento de risco, a campanha do Ministério da Saúde do governo José Sarney, de 1987, composta por cinco filmes, com o slogan "Aids: você precisa saber evitar", apresentou a síndrome como doença complexa e sem cura. Transmitiam informações sobre as formas de contágio e a importância do uso da "camisinha de Vênus". Argumentavam sobre a importância da redução de parceiros homossexuais, a necessidade de evitar o uso de seringas e agulhas descartáveis e falavam, ainda, da solidão do doente em decorrência do preconceito. (MARQUES, 2003).

No Brasil, as campanhas foram criticadas pelo seu teor e por sua divulgação esporádica, dado que realizadas apenas no Carnaval e no Dia Mundial de Luta contra a Aids ( $1^{\circ}$ de dezembro). Dessa forma, o efeito preventivo foi extremamente limitado (AYRES, 2002, p. 14). Dessa forma, foram necessárias duas décadas, no Brasil, para que o governo e a sociedade dessem respostas às demandas que surgiam. A linha norteadora da prevenção assentou-se em estratégias de prevenção visando a interromper a transmissão do vírus e retardar ao máximo o surgimento da imunodeficiência ou doenças oportunistas (OLIVEIRA, 2005, p. 86).

O Brasil foi um dos primeiros países do mundo a deixar de associar a AIDS à morte em suas campanhas. Ao contrário dessa tendência, a comunicação sobre a AIDS no país passou a privilegiar a informação, valorizando a auto-estima, incentivando o uso do preservativo e, principalmente, procurando respeita os direitos humanos. Além desse diferencial, temas considerados tabus foram abordados nas campanhas de AIDS do 
Brasil. Surgiram várias campanhas consideradas polêmicas por sua ousadia, porque se dirigiam a homens que fazem sexo com homens em 2002, a mulheres adolescentes que não têm vergonha de comprar o preservativo em 2003; em uma delas, de 1994, um homem conversa com o próprio pênis (BRASIL, Programa Nacional de DST e AIDS, 2007).

Alguns fatores fundamentais, como dados epidemiológicos, pesquisas de comportamento e a participação da sociedade civil, pautam o processo de construção das campanhas. Mas, mesmo após vinte anos do início das ações governamentais, a combinação "tratamento e informações" ainda é frágil.

Ayres (2005) afirma que a adesão do auditório ao orador é o aspecto mais importante da prevenção. Para o pesquisador, as teorias da comunicação precisam ser retomadas, para oferecerem aos estudiosos elementos para evitar os preconceitos, como exclusão de crianças soropositivas de escolas, a demissão de portadores do vírus de seus empregos e outros constrangimentos (AYRES, 2005).

O HIV, do ponto de vista biológico, é um vírus que atinge um sistema vital do corpo humano: as células de defesa do sistema imunológico. Do ponto de vista cultural, o HIV está ligado à sexualidade. Isto significa que a compreensão da síndrome, de seus modos de transmissão, de suas patologias e curas vai muito além da biologia. A síndrome AIDS evoca muitas questões, das culturais às educacionais e, como afirmou Ayres (2002), da boa comunicação.

Estes problemas, no início da década de 80 ainda não estavam claros (AYRES, 2002). Dessa maneira, as primeiras campanhas de prevenção valorizaram o medo como pedagogia da comunicação. A AIDS era associada à morte, com a pretensão de, com isso, conseguir rápida adesão ao uso do preservativo. A morte era apresentada como uma ocorrência rápida; considerando-se a infecção como o início e o fim da vida da pessoa soropositiva. Como diz Giami (1977, p. 71),

A associação entre AIDS e morte mostra uma definição da Aids que engloba, numa mesma representação, a contaminação e a soropositividade, assim com a doença declara desde a sua primeira até a sua última fase. Vista sob este ângulo a Aids nem parece uma "doença", mas um estado que provoca morte rápida e inelutável

A representação da AIDS como morte imediata cria outro sentido: a sexualidade está próxima da morte. Sexo é uma prática mortal. Este primeiro momento das 
campanhas vinculou uma prática humana e afetiva à culpa. Somos culpados pela nossa síndrome; somos culpados até pela nossa morte. Estávamos, então, lidando com uma perigosa argumentação: infecção é morte, logo sexo é morte. AIDS, doença, saúde e sexualidade são dimensões entrelaçadas, nesse caso, com a idéia de morte e culpa.

De 1980 a 2007 houve transformações no modo de conceber as campanhas preventivas de HIV/Aids; no decorrer dessas décadas passou-se a ressaltar a importância da sexualidade na comunicação das informações científicas de prevenção, o que vem mudando a cultura de prevenção à síndrome. Imagens mais alegres, mesmo se de homens com homens, são mais aceitas. Os argumentos do medo e terror são aos poucos abandonados; essa nova conduta implicando em outra forma de explicar a síndrome e os riscos a ela associados sem afastar os soropositivos do tratamento e sem nos amedrontar com o caminho dessa epidemia.

Diante desse debate sobre o HIV/Aids, propusemo-nos a analisar, por meio da retórica, imagens e os textos de campanhas de prevenção do HIV/Aids. Utilizamos, para nosso exame retórico, as campanhas acerca do HIV/Aids produzidas, no período de 2000 a 2006, no Brasil, Argentina, França, Estados Unidos e Portugal. Consideramos campanhas tanto as produzidas pelo poder público quanto pela iniciativa privada, uma vez que todas são divulgadas à população pela mídia (revistas, jornais, entre outros) e pelos serviços de saúde.

Nossa investigação, cujo objetivo foi examinar textos e imagens de campanhas de prevenção ao HIV/Aids para conhecer os sentidos produzidos por essas campanhas, norteou-se pelas seguintes questões: "qual ou quais são os sentidos empregados nas campanhas?"; "são sentidos que nos aproximam do problema da prevenção ou não?". A investigação, a nosso ver, se justifica por acreditarmos que a o conhecimento do que as imagens e textos comunicam em uma situação de informação científica nos auxilia a detectar as ferramentas da argumentação, a corrigi-las ou aprimorá-la.

Para o exame retórico do discurso dos textos e imagens das campanhas, os trabalhos de pesquisadores como Reboul (1998), Perelman Olbrecrhs-Tyteca (2005), Lakoff e Johnson (2002), Breton (2003), Mazzotti (2005) e Gaskell e Bauer (2005) constituíram em nosso referencial. Para referendar nossas observações sobre a história das campanhas de prevenção do HIV/Aids utilizamos Ayres (2002; 2005), Paiva (2005), Marques (2003) e Saraceni (2003).

Quanto aos procedimentos metodológicos, optamos por utilizar imagens, com ou sem texto, de algumas campanhas de prevenção ao HIV/AIDS retiradas da internet. A 
seleção das campanhas levou em conta os seguintes critérios: 1) Local em que a campanha foi produzida, 2) Data ou período de divulgação, 3) Origem: governamental ou não governamental (privada). Para a análise, organizamos as imagens levando em consideração a cor, a disposição dos elementos, o tamanho e o texto (quando havia).

\section{A RETÓRICA COMO TEORIA PARA O EXAME DAS CAMPANHAS DE PREVENÇÃO AO HIV/Aids}

Há três dimensões da Retórica, O Ethos, o Pathos e o Logos. O Ethos é o caráter que o orador deve assumir para inspirar confiança no auditório, um termo moral e ético (REBOUL, 1998). Breton (2003, p.37) caracteriza esta dimensão como a do "orador", aquele que argumenta, para si mesmo ou para outros.

Bauer e Gaskell (2005) definem o Ethos como uma forma de argumentação persuasiva que se fundamenta na credibilidade do autor, ou locutor. Podemos afirmar, ainda, de acordo com Bauer e Gaskell (2005), que o orador pode lançar mão do ethos para apresentar afirmações mais fortes.

O Pathos consiste no conjunto de emoções, paixões e sentimentos que o orador deve suscitar no auditório com seu discurso (REBOUL, 1998, p.166). Ainda conforme Bauer e Gaskell (2005), o Pathos compreende uma forma de argumentação persuasiva, porque apela à emoção. A publicidade apresenta inúmeros de exemplos desse tipo. $\mathrm{O}$ apelo chamativo "mais pesquisa é necessária", é extremamente persuasivo quando são mencionadas aplicações para curas, ou remédios para doenças dolorosas, ou aplicações para saúde das crianças (BAUER; GASKELL, 2005).

O Logos diz respeito à argumentação propriamente dita do discurso. É o aspecto dialético da retórica (REBOUL, 1998, 39). Parte da retórica, o logos consiste no exame de como os argumentos lógicos funcionam para nos convencer de sua validade. Pensar o logos é pensar o poder do discurso em conformar ou construir determinadas cosmovisões (BAUER; GASKELL, 2005).

Essas definições são importantes uma vez que examinamos imagens e textos de campanhas de prevenção ao HIV/Aids do ponto de vista de suas argumentações e de possibilidade de adesão a elas pelo leitor/auditório. As imagens são importantes recursos para a comunicação, também são argumentos, na medida em que contribuem para a inteligibilidade de diversos textos científicos. 
A relação orador/logos/auditório pode ser exemplificada como uma opinião (tese, causa, idéia) que é comunicada por um orador (que visa a transportar essa idéia para o auditório), que tenta, por meio de um argumento (opinião formada para convencer), persuadir o auditório em um contexto de recepção (conhecimento prévio) (BRETON, 2003).

O logos deve ser formulado conforme o auditório, e, por isso, pode ser apresentado de diversas maneiras. A transformação do modo como se apresenta o assunto não implica numa mudança no argumento, mas sim de sua abordagem (BRETON, 2003).

Pensando nesta relação discursiva, podemos perguntar: no que consiste a análise retórica do discurso e da imagem? Este tipo de análise interessa-se pela estrutura do discurso proferido em público.

Segundo Reboul (1998), na teoria retórica a imagem está a serviço do discurso. Ao ser usada para destacar idéias, ela se torna uma importante ferramenta no mundo da comunicação, medida em que atenua, reforça, ou até substitui a mensagem a ser apreendida pelo público.

Para Santaella (2001, p. 22), a comunicação é inevitável porque, mesmo quando não queremos, estamos emitindo mensagens para o outro e isto ocorre o tempo todo. Ela é irreversível, pois não podemos voltar atrás do que já foi comunicado. Reboul (2005) argumenta que, historicamente, os homens comunicaram-se bem mais pela imagem do que pelo texto.

Numa definição mais ampla e geral, a comunicação pode se expressar pela transmissão de qualquer influência de uma parte de um sistema vivo ou maquinal para outra parte, de modo a produzir mudanças (SANTAELLA, 2001, p. 22). Assim, as imagens são contextualizadas pelo leitor, que as interpreta, gerando, para ele, algum significado.

Uma figura, imagem ou idéia transmite um conhecimento ao seu intérprete, que quase não precisa de léxico lingüístico para entender o texto. O que se pretende mostrar é que as imagens podem revelar figuras de retórica como as levantadas nas gramáticas do verbal, produzindo significados indispensáveis para um entendimento do texto (BAZANI, 2005).

O exame retórico de imagens é medido pela habilidade em dizer sobre o particular e o possível, o objetivo principal desse exame é compreender o poder de persuasão das imagens sobre o auditório. 
As figuras de retórica são fartamente conhecidas como as clássicas figuras de linguagem, sobretudo, as idéias de similaridade (metáfora) e de contigüidade (metonímia). A retórica desenvolveu uma série de figuras de linguagem, de pensamento e de sintaxe com o objetivo de construir meios, até mesmo estilísticos, para conseguir adesão de sujeitos participantes de um ato oratório (BAZANI, 2005).

Aprender o significado não-verbal de um texto qualquer em sua materialidade significante é ver que essa forma de discurso também é carregada de significado. Sabese que o verbal ancora o não verbal e vice-versa, mas isso não significa que um pode ser eliminado em detrimento do outro.

A argumentação visa à adesão do auditório a certas teses, no caso da publicidade a aceitação do produto. As técnicas argumentativas se apresentarão sob dois aspectos diferentes. O positivo consiste no estabelecimento de uma solidariedade entre as teses que se procura promover e as já admitidas pelo auditório: trata-se de argumentos de ligação. $\mathrm{O}$ aspecto negativo visa abalar ou romper a solidariedade constatada ou presumida entre as teses admitidas e as que se opõem às do orador: trata-se aqui dos argumentos de dissociação, da ruptura das ligações (PERELMAN e OLBRECRHS TYTECA, 2005, p. 211).

Deste modo, argumentar, convencer e persuadir são princípios da Retórica. Perelman e Olbrecrhs-Tyteca (2005) propõem-se a estudar as técnicas discursivas que permitem provocar ou aumentar a adesão às teses apresentadas ao seu assentimento. Esta busca pela adesão a uma determinada tese é o que podemos chamar de ato de convencer (PERELMAN, 2005).

Para Reboul (2003), a principal figura retórica é a metáfora. Esta consiste em uma comparação entre dois elementos por meio de seus sentidos imagéticos, que causa o efeito de atribuição "inesperada" ou improvável de significados de um termo a outro. Podemos argumentar ainda que a metáfora é um tropo, uma mudança bem sucedida de significações de uma palavra ou de uma locução (PERELMAN; OLBRECTHSTYTECA, 2005).

Mas as metáforas não são meramente fenômenos que devem ser decifrados. De fato, como argumentam Lakoff e Johnson (2002), só é possível decifrá-las usando outras metáforas. É como se a habilidade de compreender a experiência por meio da metáfora fosse um dos cinco sentidos, como a visão, o tato, a audição. O que significa dizer que nós só percebemos e experimentamos uma boa parte do mundo por meio de 
metáforas. A metáfora é parte tão da nossa vida como o toque, é tão precisa quanto (LAKOFF; JOHNSON, 2002).

As metáforas fazem parte da cultura de uma determinada sociedade. Desse modo, em cada sociedade culturalmente estruturada há uma construção metafórica da linguagem que constitui o pensamento e a ação das pessoas (LAKOFF; JOHNSON, 2002). A metáfora rege nossos pensamentos e nossas ações em todas as áreas de nossas vidas. Os autores afirmam que, embora o conhecimento da realidade tenha origem na percepção, na linguagem ou na memória, é necessário ir além da informação dada.

\section{EXAMINANDO AS IMAGENS DAS CAMPANHAS DE PREVENÇÃO CONTRA O HIV/Aids}

Em nossa investigação, optamos, para a análise retórica das 12 imagens e textos de campanhas do Brasil, Portugal, Alemanha, Argentina, França e EUA, no período de 2000 a 2006, pela abordagem qualitativa fundamentada em Bauer e Gaskell (2005).

Uma campanha se caracteriza pela formulação e explicitação de um ou mais objetivos que o proponente (emissor) pretende atingir ao apresentar uma dada informação. Tais objetivos, segundo Sacchi (2005) podem se constituir na intervenção sobre os conhecimentos, as atitudes ou as habilidades do público (receptor), mediante o emprego de uma variedade de meios de comunicação que, trabalhados articuladamente, contribuem para o sucesso da campanha. As campanhas de prevenção a HIV/Aids são enquadradas como campanhas de mudança social porque buscam convencer terceiros a aceitar, modificar, ou abandonar certas idéias, atitudes, práticas e comportamentos (HIDELBRAND, apud SACCHI, 2005).

Em uma campanha de prevenção a HIV/AIDS, o uso da imagem e da representação da camisinha ou do órgão sexual ultrapassa sua denotação puramente sexual e avança como signo de proteção em si. Para Xavier (1997), a camisinha é representada protegendo não apenas indivíduos da contaminação por meio do ato sexual, mas protegendo tudo o que envolve a sexualidade humana, o casamento, o sexo, os órgãos genitais e o amor.

Para compreender melhor os argumentos contidos nas imagens das campanhas preventivas sobre HIV/Aids, Xavier (1997) personifica a Aids principalmente de cinco maneiras: 
a) Como um monstro, representando terror e perseguição. Esta imagem remete a horrores antigos, mitológicos, que ultrapassam em muito o caráter da doença, carregando em si o pânico pelo nãoconhecido

b) Como vírus, revelando impessoalidade e sua natureza biológica. Mas, na grande maioria das vezes em que a Aids é assim retratada, tais vírus parecem pequenos monstrinhos devoradores

c) Como a morte, seja como um esqueleto ou com uma clássica figura negra com a foice. Aqui a doença passa a ser representada não por seu agente ou por suas implicações, mas por sua (suposta) conseqüência ultima. Desperta um forte vinculo imaginário entre Aids e Morte.

d) Como o diabo. A escolha deste signo envolve a dicotomia bem/mal. A Aids aqui é vista não apenas como algo que é mau em relação à saúde do homem, mas como mal em si.

e) Como a palavra Aids, com as letras ligadas ou não entre si formando uma espécie de "ser". Maneira abstrata e convencional de representar, calçada exclusivamente na força do imaginário à simples menção do nome da doença. Neste caso, "o nome é a coisa" (XAVIER, 1997).

\section{Análise retórica da prevenção sobre HIV/AIDS}

Apresentamos, a seguir, a análise retórica das campanhas de prevenção ao HIV/AIDS do período de 2000 a 2006, dos países: Brasil, França, Portugal, Argentina e Estados Unidos (neste último caso, uma das imagens é de um filme) .

CAMPANHA 1 - França: esta imagem faz parte da campanha preventiva elaborada pelo Ministério de Saúde Francês, em 2004 e 2005. 


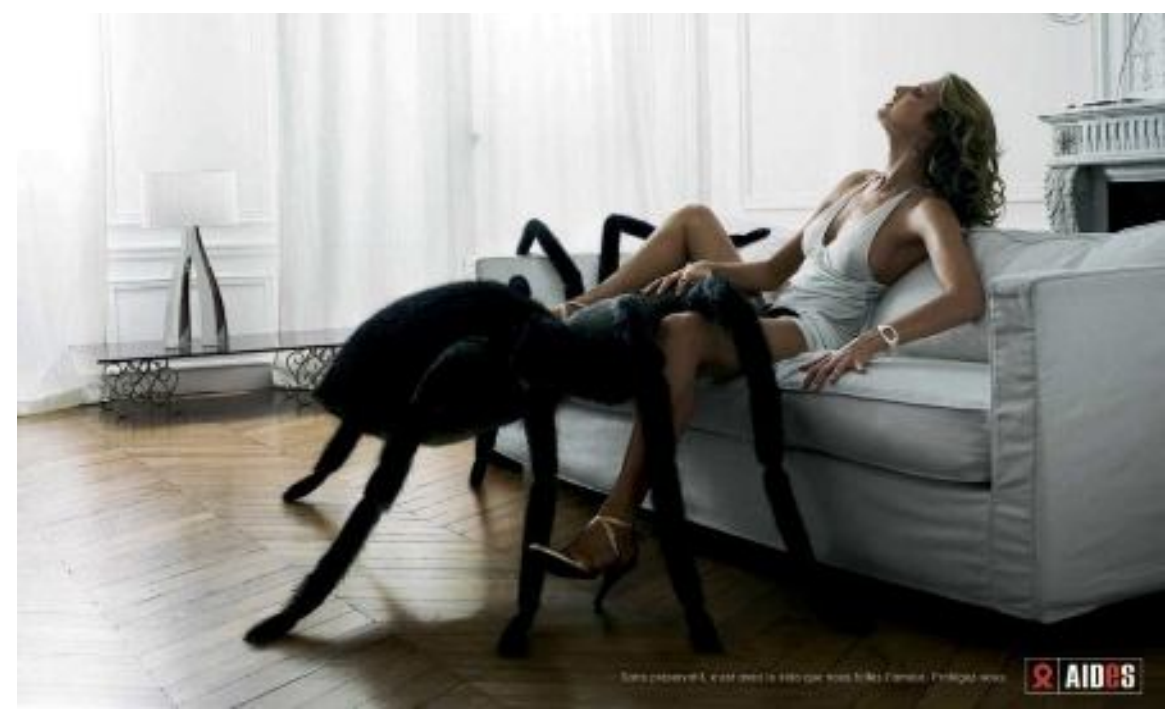

Esta imagem leva o auditório, em um primeiro momento, ao susto, à rejeição porque ela sugere uma relação sexual entre um aracnídeo e uma mulher, uma idéia inusitada entre nós. Como a imagem de aracnídeos, na sociedade ocidental, sugere perigo, envenenamento e morte, a metáfora nessa imagem pode produzir o sentido "sexo é morte". Sexo é "veneno", é "perigoso", significa a possibilidade de morte.

CAMPANHA 2 - Campanha de saúde brasileira, realizada no carnaval de 2001, organizada pelo Ministério da Saúde.

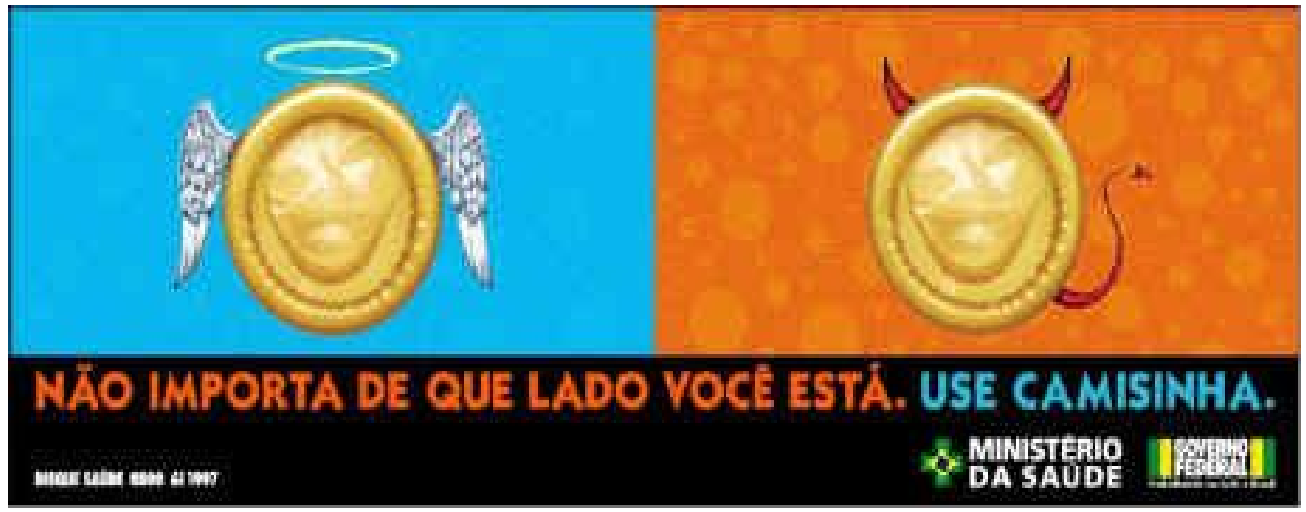

O texto da campanha 2 apresenta o slogan "Não importa de que lado você está, use camisinha". Focaliza a percepção individual sobre as situações de risco e vulnerabilidade. A imagem, que dispõe duas camisinhas representando um "anjo" e um "diabo", sugere ao auditório que, na festa do carnaval, festa pagã, pode-se optar entre duas condutas: "comedidos" ou "exagerados" não importando de que lado você está. 
CAMPANHA 3 - Trata-se de uma campanha brasileira, organizada pelo Ministério da Saúde, Secretaria de Políticas de Saúde e Coordenação Nacional de DST e AIDS e realizada em setembro de 2002.

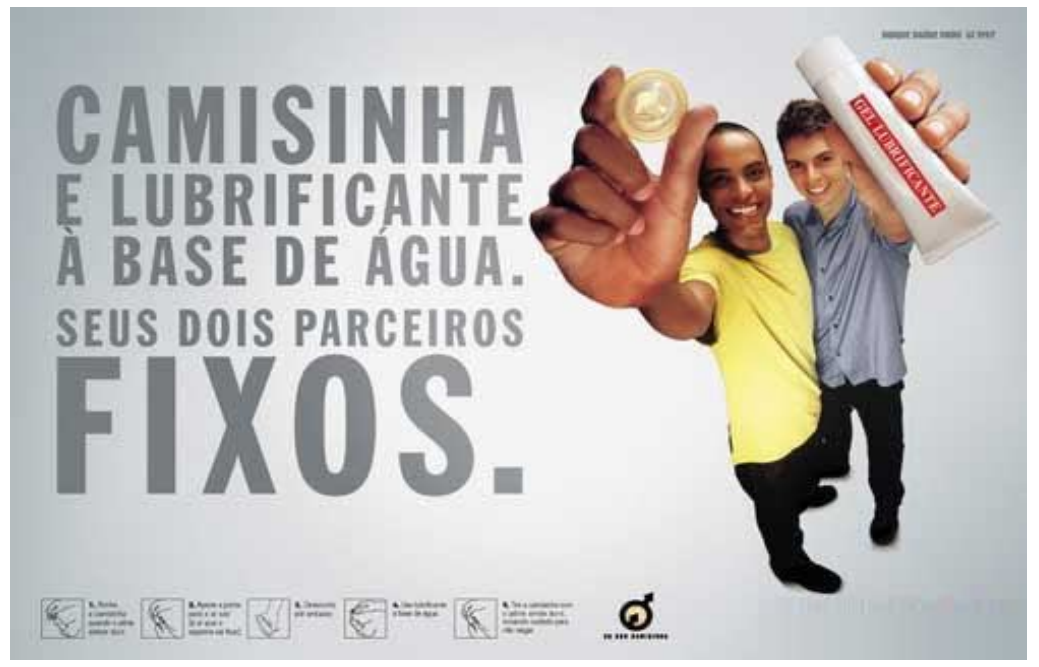

A imagem da campanha apresenta um casal homossexual, um preservativo e um lubrificante à base de água. Ao apresentar um casal formado por dois homens, um negro e um branco, ela sugere o não preconceito em relação à homossexualidade e à etnia. Os rapazes estão sorrindo, as roupas são coloridas, o que torna a imagem alegre e suave para o público. O zoom nas mãos aumenta a visualização do preservativo e do lubrificante e os destaca em primeiro plano. O tamanho das letras do texto enfatiza a importância do uso do preservativo. A imagem sugere tranqüilidade na prevenção.

CAMPANHA 4 - Esta imagem é da campanha preventiva realizada pelo Ministério da Saúde Francês, no período de 2004 e 2005. 


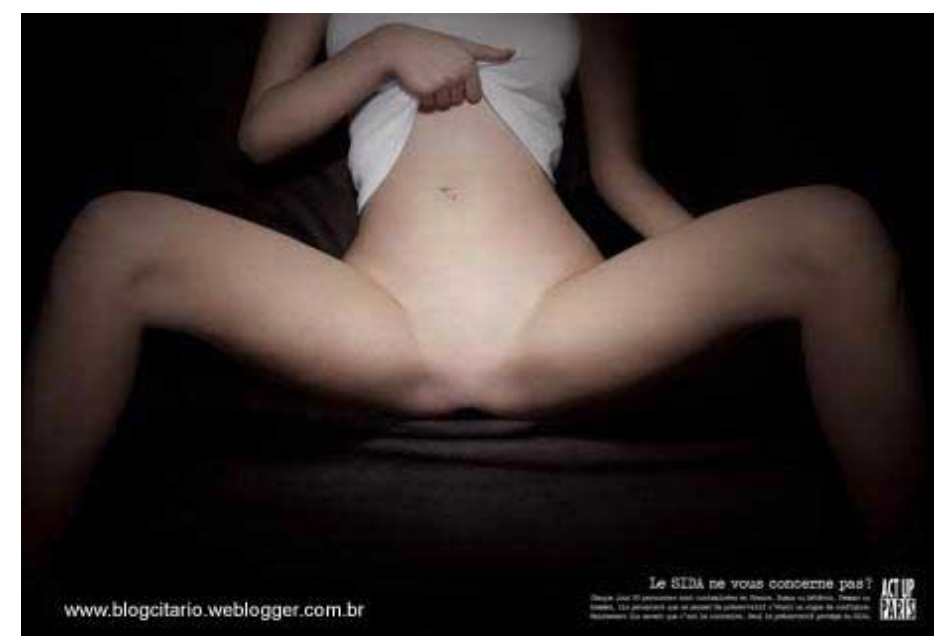

Com os dizeres “A Aids não te diz respeito?”, apresenta a imagem de uma mulher branca, magra, padronizada como bela por nossa sociedade. Mas, vê-se a ausência de órgãos genitais e, inclusive, a cabeça. Um possível sentido pode ser constituído com a mensagem: uma mulher assexuada não corre risco de contaminação. Suprimindo-se o sexo, suprime-se o problema. Podemos analisar a imagem pela:

1. Metáfora: O contraste das cores, o corpo branco e fundo preto realçam a perna e a ausência dos "órgãos genitais", o que sugere que a segurança contra a infecção por HIV/AIDS está na abstinência sexual. É possível ao auditório compreender, mediante essa campanha, que sexo seguro é o não sexo, que a relação sexual é a porta para a infecção pelo HIV/AIDS. A ausência do órgão genital indica que o sexo é a Aids.

2. Metonímia: a imagem sugere que se abster do sexo é se prevenir.

CAMPANHA 5 - Esta imagem faz parte da campanha preventiva, elaborada pelo Ministério de Saúde Francês, em 2004 e 2005.

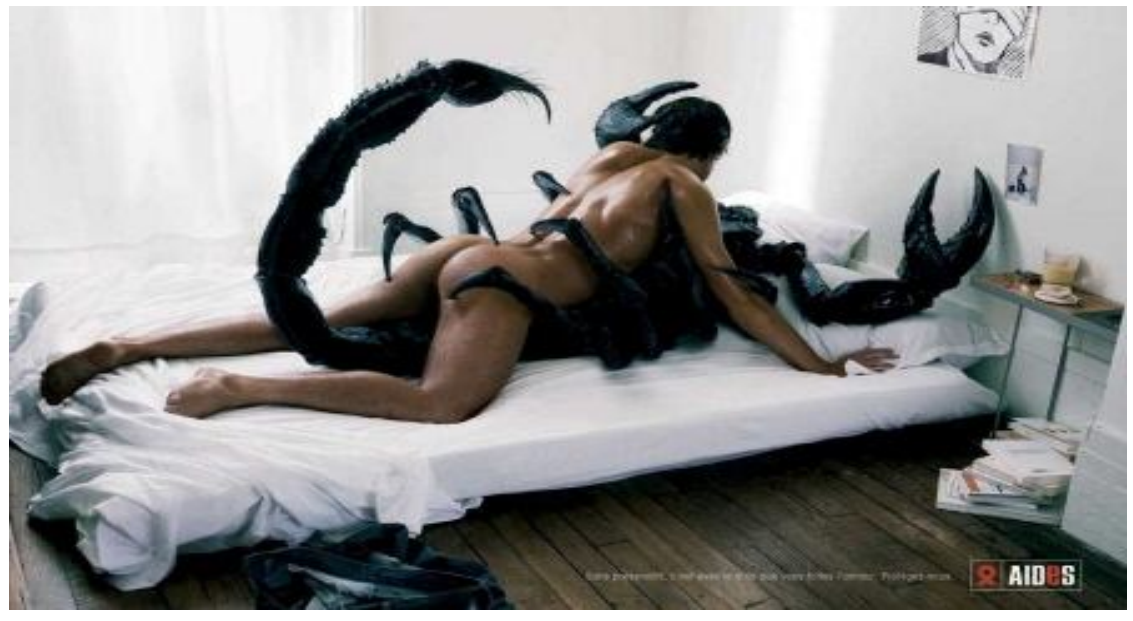


Esta imagem da campanha francesa também pode despertar medo no leitor/observador. Aponta a relação sexual como algo perigoso à vida humana, situação que afasta as pessoas do entendimento da noção de sexo seguro. A metáfora "sexo é fatal" pode criar o sentido: sexo é infecção e morte.

Se a sociedade já tem preconceitos diante da sexualidade, esta imagem parece exacerbá-lo. Ao sugerir, em um primeiro momento, que o sexo pode conduzir as pessoas a encerrar sua vida, leva-as não só ao medo da morte, mas também ao terror diante do sexo que, sabemos que é biologicamente essencial à proliferação das espécies. $\mathrm{O}$ contraste entre as cores brancas e pretas também podem sugerir ligação à morte.

O medo como estratégia de convencimento de algo ou de uma idéia, como apresentado por Ayres (2002), não é o caminho que permite uma compreensão dos perigos relativos à síndrome, nem mesmo ao desenvolvimento de uma cultura de prevenção.

Destaca-se o paradoxo como figura retórica, pois a relação sexual entre um ser humano e um escorpião são idéias antagônicas e inconciliáveis, embora alcancem o imaginário.

CAMPANHA 6 - Campanha de saúde brasileira, organizada pelo Ministério da Saúde e realizada no Carnaval de 2002.

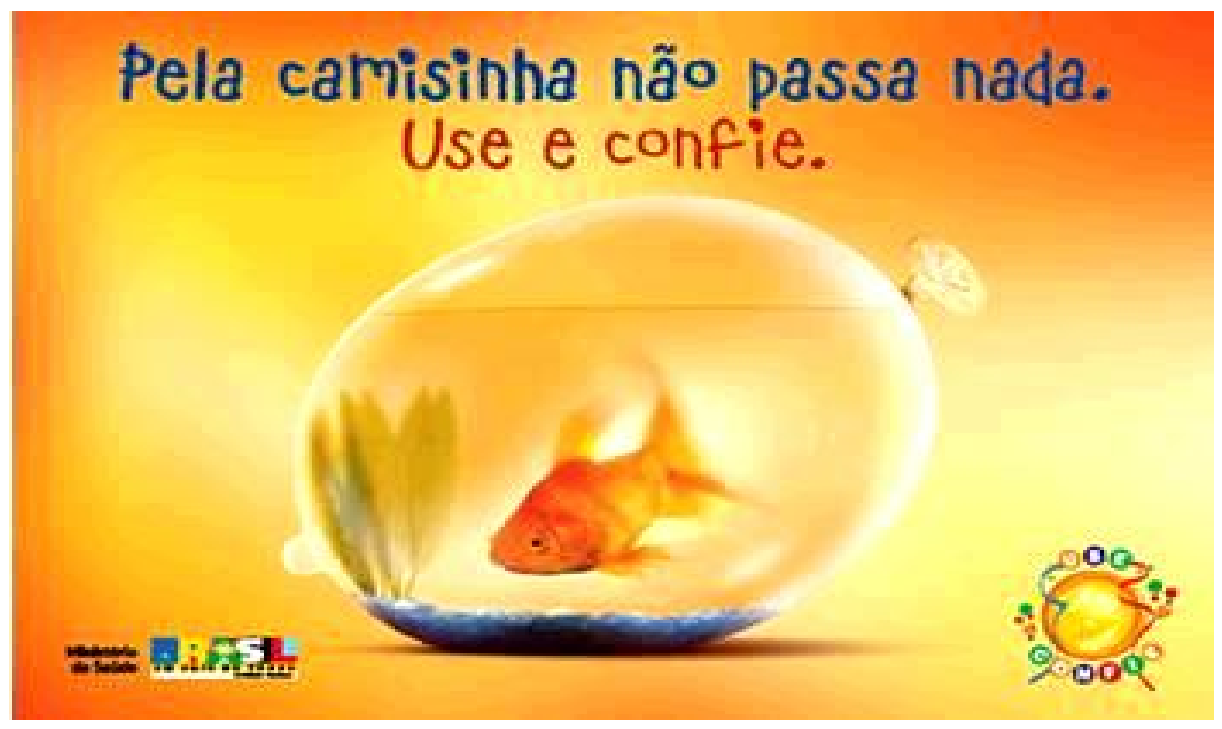

Esta imagem da campanha preventiva sugere a confiabilidade em um produto, a camisinha, no período do Carnaval, festa popular brasileira.

O fato de a camisinha estar cheia de água sugere confiabilidade, porque podemos imaginar que, se a água não passa pelo material, muito menos o vírus do HIV/Aids. Esta 
representação sugere uma "certa" tranqüilidade por apresentar a camisinha como o habitat de um peixe e de plantas aquáticas. Ora, se este habitar permite a vida e, tudo leva a crer que a camisinha é segura. Daí poderia surgir a metáfora que "camisinha é igual à vida".

O slogan "pela camisinha não passa nada" remete à idéia de uma "barreira", uma metonímia que leva o público a sentir segurança. As cores vivas, como a laranja, sugerem a sensação de alegria, festa, verão e diversão. Esta ligação com alegria é persuasiva porque, na cultura brasileira, dizer que se está alegre é dizer que tem vida.

CAMPANHA 7 - Campanha sobre o filme "O PRESENTE (The Gift) (EUA, 2003, 62 min Direção: Louise Hogarth) - prevenção ao HIV/Aids nos Estados Unidos

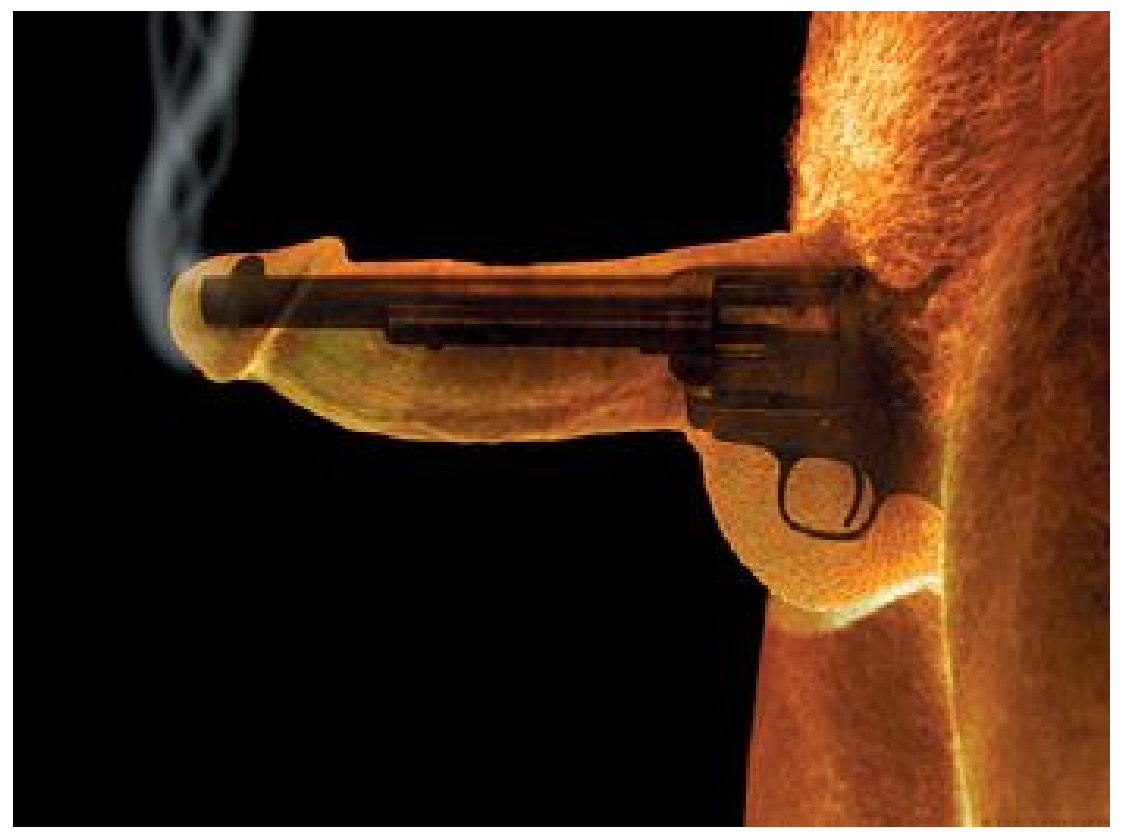

A imagem apresenta um pênis como uma arma de fogo. Demonstra, por meio do pênis/arma, a possibilidade da morte (metáfora). Sexo pode ser fatal. Temos, aqui, a hipérbole, a figura do exagero, devida à Aids ser apresentada como a morte fulminante

CAMPANHA 8 - Campanha publicitária da Tulipan (indústria de preservativos) da Argentina, sobre a importância do uso do preservativo (camisinha), apresentada em várias emissoras de TV em 2005. 


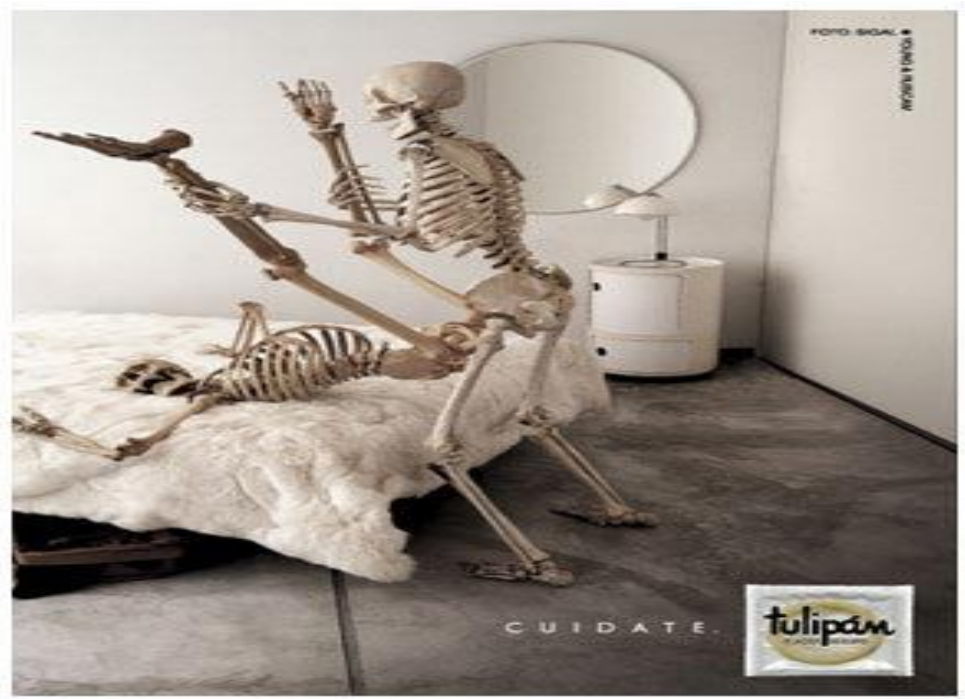

A campanha publicitária argentina tem por objetivo a adesão das pessoas ao preservativo, dada a possibilidade de morrer ao praticar sexo sem seu uso. Isso é feito mostrando duas caveiras em relação sexual, sugerindo a metáfora que "sexo é igual a morte", como vimos também nas campanhas francesas.

O uso do conceito de morte ligada à prática sexual sem o uso do preservativo transforma este em sinônimo de vida. O que pode até sugerir a metáfora, "use e viva" para o cotidiano das pessoas.

É possível, ainda, observar que o quarto onde ocorre o ato sexual tem a cor branca, que na sociedade ocidental tem o significado de algo puro, moralmente correto ou ainda higienizado e limpo. Cabe aqui, também, notar que o espelho contido no quarto não reflete os sujeitos (esqueletos) o que pode sugerir que estes não existem mais, não têm mais vida.

CAMPANHA 9 - Campanha da ONGs CAJIXIRA - Centro de Apoio à Juventude e à Infância, de Vila Franca de Xira, em Portugal, no ano de 2001. 


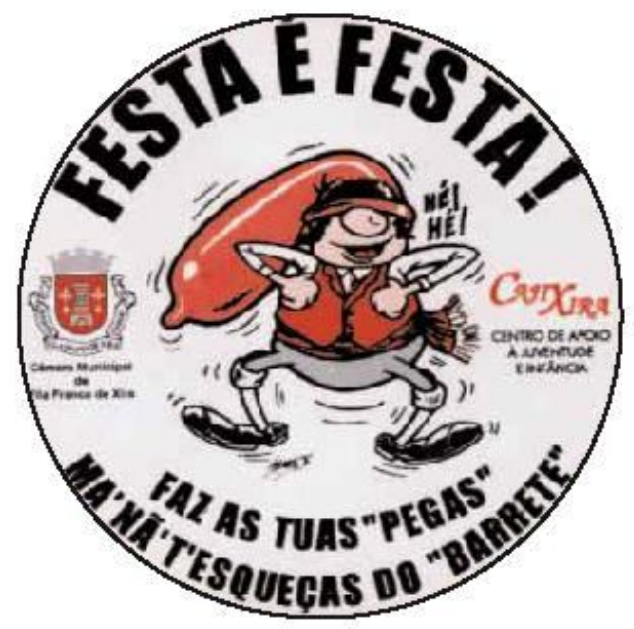

O humor pode ser uma forma privilegiada de persuasão na difusão das mensagens. Ciente disso, o CAJIXIRA, Centro de Apoio à Juventude e à Infância, de Vila Franca de Xira, em Portugal, desenvolve várias campanhas de sensibilização e informação sobre Aids, recorrendo a imagens humorísticas (PORTUGAL, 2001).

A imagem corresponde a uma pessoa indo a uma festa local, informando que a sexualidade deve ser praticada, mas não se deve esquecer o preservativo, a uma camisinha ou "BARRETE". É um alerta da ONG para os perigos da infecção pelo HIV/Aids. Vê-se na imagem que o sujeito está feliz (o "Hê! Hê!" representando satisfação) dirigindo-se à festa protegido.

CAMPANHA 10- Campanha preventiva do ministério da Saúde Francês nos anos de 2006 e 2007. 


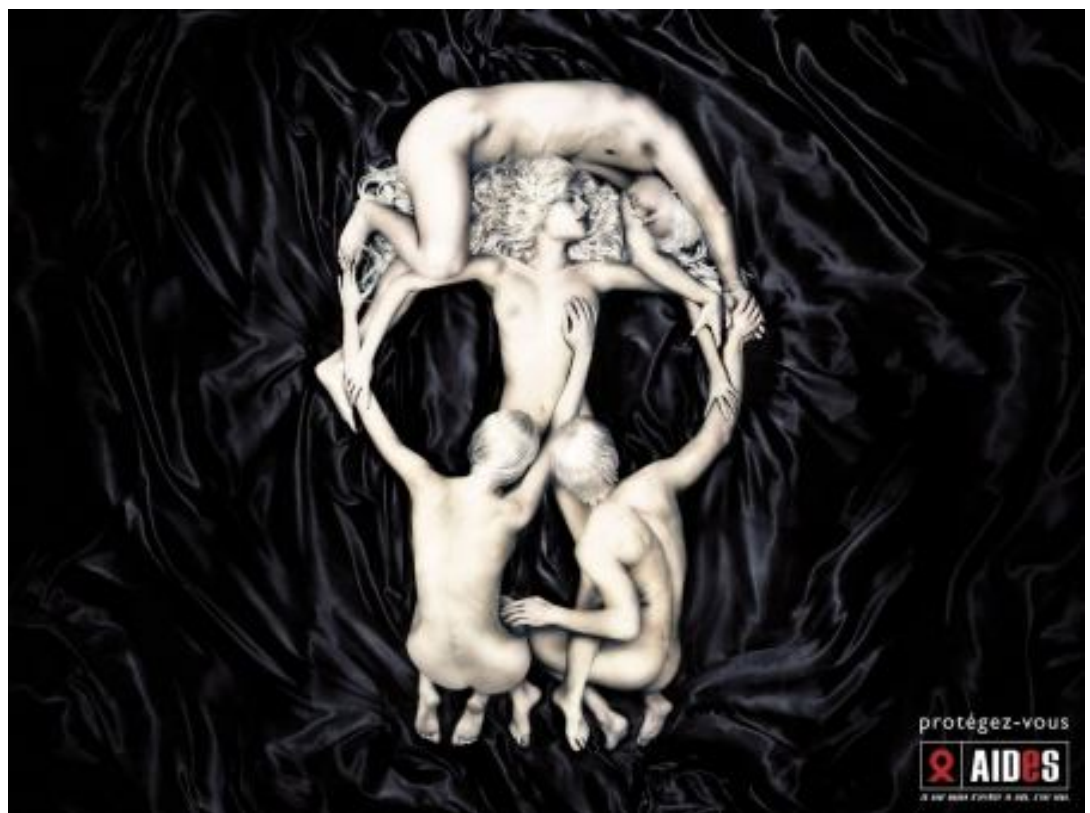

A campanha francesa mostra pessoas brancas sobre um fundo preto formando com seus corpos a figura de um crânio humano. A metonímia crânio representa o perigo de morte (como nos rótulos de produtos químicos). A imagem da campanha preventiva francesa quer levar a crer que a Aids é mortal.

CAMPANHA 11 - Campanha da GOAS (Grupo de Orientação e Assistência a Saúde), uma organização não governamental da cidade de São Paulo, realizada em 2005.

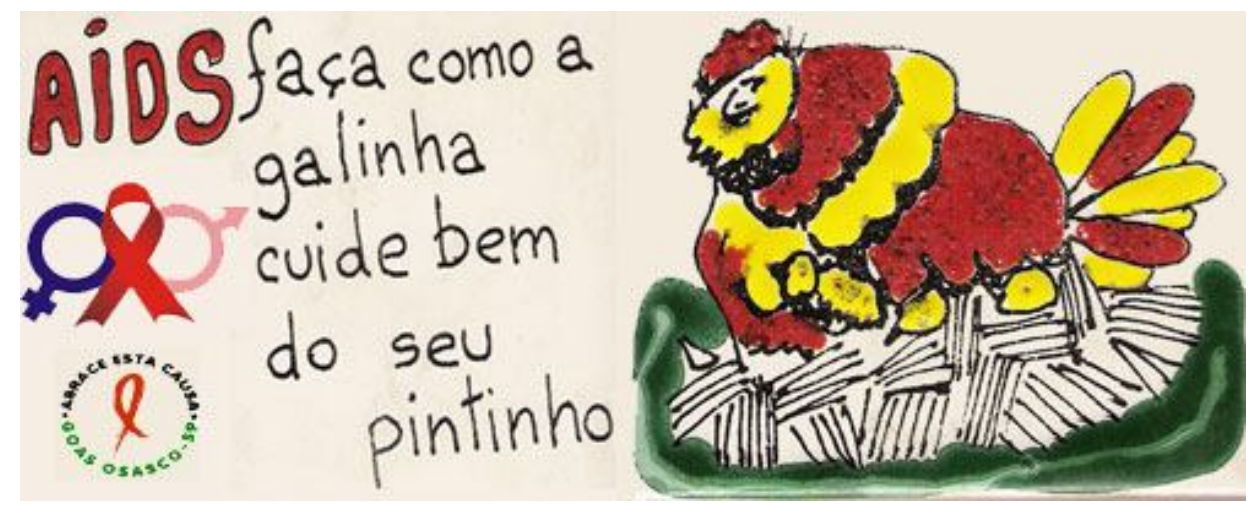


O GOAS, uma instituição filantrópica e sem fins lucrativos, foi constituída com o objetivo de investir em programas de cunho social, preferencialmente para famílias e pessoas mais carentes, portadoras do vírus HIV/Aids e dependentes químicos, na zona oeste da grande São Paulo.

A campanha, local, foi realizada na região metropolitana da cidade de São Paulo e ocorreu no ano de 2005. É clara a utilização do humor para ganhar a adesão do público para a prevenção contra o vírus da Aids. Como "pintinho" é uma figura (metáfora) associada ao órgão genital masculino; a campanha pretende tornar sua mensagem acessível à maioria das pessoas, já acostumadas a estabelecer esta ligação e tornando-a agradável. Remete o público ao cuidado de si como fazem as aves.

A cor vermelha e amarela são cores que despertam no olhar a atenção e estimulam a alegria. Não sendo necessário uma campanha com imagens que despertem medo ou mesmo informações errôneas sobre a questão do HIV/Aids .

CAMPANHA Nº 12 - Ministério da Saúde dos Estados Unidos ano de 2005.

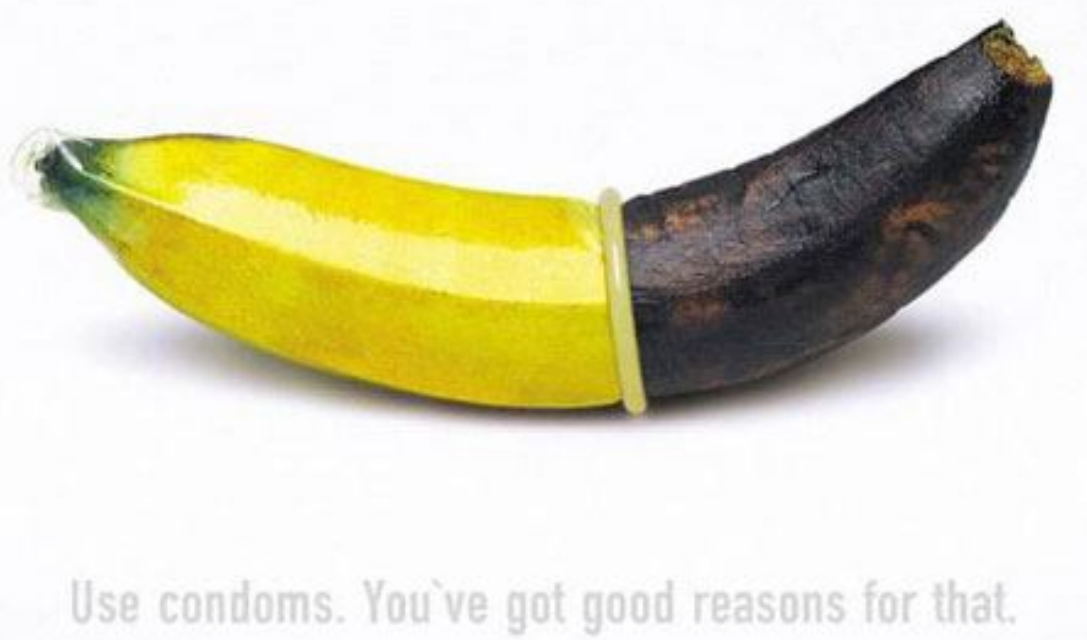

"Use camisinha. Você tem ótimas razões para isso." Quais são essas razões? Mais uma vez a imagem da campanha de prevenção vincula o sexo ao mal, à doença. Essa banana, utilizada como analogia ao pênis humano, mostrar-se podre pode criar um sentido sexo é ruim. A fruta, representando o órgão masculino, ainda nos remete à noção de que o HIV/Aids é uma doença do sexo masculino (PAIVA, 2003). 


\section{CONSIDERAÇÕES FINAIS}

Como vemos, existem campanhas que utilizam figuras como argumentos retóricos para persuadir o auditório a uma tese. Algumas buscam persuadir o leitor gerando medo. Pode-se afirmar que nas campanhas francesas de 2004 e 2005, na argentina de 2005 e nas americanas de 2003 e 2005 circulam sentidos de terror à síndrome e sua prevenção.

Como citamos anteriormente, na introdução deste artigo, Ayres (2002) chama a atenção para o tipo de comunicação e sentidos gerados pela educação aliada ao medo. Para nós, essas campanhas podem ser evitadas porque ao medo e ao terror vincula-se o preconceito. O preconceito gera a discriminação e estes mantêm e disseminam estigmas e atitudes dogmáticas.

As campanhas brasileiras e a portuguesa apresentadas optaram por outros recursos retóricos. Sugerem alternativas mais agradáveis e mais informativas. Na comunicação agradar e informar são boas qualidades para mensagens mais plurais e dialógicas de respostas à epidemia. Ora, a sexualidade é uma dimensão humana essencial; "faz parte de nossa condição humana, faz parte da liberdade em nosso usufruto desse mundo", como disse Foucault. Seu exercício está ligado à nossa intimidade, sensações,

sentimentos e emoções. É, então, muito importante, que mensagens agradáveis e informativas, sejam aliadas, da liberdade humana de usufruir a sexualidade e suas dimensões, sem que o medo e o preconceito a invalidem como expressão de ser e estar no mundo.

As campanhas brasileiras e a portuguesa mostram, ainda, que a Aids ocorre em diversos grupos sociais, étnicos e sexuais, marcantes em nossa cultura brasileira. $\mathrm{O}$ silêncio a esses aspectos nas demais em campanhas preventivas sobre o HIV/Aids apresentadas desperta a necessidade de enfrentar o desafio de combater a discriminação e o preconceito nelas facilmente observados. Medo, terror, preconceito e discriminação levam o portador da síndrome Aids à exclusão de direitos democráticos historicamente construídos e conquistados pelo ser humano.

As campanhas de prevenção para HIV/Aids realizadas e as que ainda teremos que fazer necessitam da educação e retórica. Como arte da comunicação, a retórica é ferramenta essencial para que as campanhas preventivas ao HIV/Aids possam ser melhor compreendidas pela população, conscientizadas da importância da epidemia e da necessidade de sua adesão a formas de impedir que esta se alastre. Como enfatizou Ayres (2005) a teoria da comunicação deve ser uma das ferramentas para a elaboração 
das campanhas que eduquem para a prevenção com democracia e esclarecimento. Democracia e esclarecimento são alicerces para a liberdade, aspecto importante da nossa autoconsciência e da história que nos compõe como indivíduos e cultura.

\section{REFERÊNCIAS}

AYRES, Jose R. C. Mesquita. Entrevista: José Ricardo Ayres. ComCiência - Revista Eletrônica de Jornalismo Científico. Radis nº40, dezembro de 2005.

AYRES, Jose R. C. Mesquita. Práticas Educativas e prevenção de HIV/Aids : lições aprendidas e desafios atuais. Interface - Comunicação e saúde educativa, v6, n11, p. 11-24, agosto de 2002.

AYRES, Jose R. C. Mesquita. Epidemiologia e emancipação. Rio de Janeiro: Hucitec, 1994

BASTOS, F.I.;BOSCHI-PINTO, C.;TELLES, P.R. O não dito da Aids. Cadernos de Saúde Publica, Rio de Janeiro, 9(1): 90-96, jan./mar.1993.

BAUER, Martin ; GASKELL, George. Pesquisa Qualitativa com texto, imagem e som. São Paulo: Vozes, 2005.

BAZANI, Patrícia. In: www.contexto.com.br/convicomartigoPatriciabazani.htm, acesso em 10 de maio de 2007.

BELLINI, Marta; FRASSON, Priscila Caroza. A metáfora guerra na comunicação das idéias de HIV/Aids em livros didáticos. Revista Brasileira de Estudos pedagógicos RBEP n. 217, dezembro de 2006.

BRASIL, Ministério da Saúde. As Cartas da Promoção da Saúde. Brasília: Ministério da Saúde. 2002. Disponível em www.saude.gov.br/bvs/conf_tratados.html. Aceso em 20 de novembro de 2004.

BRASIL, Ministério da Saúde. Coordenação Nacional de DST/AIDS. Aderência ao tratamento por anti-retrovirais. Brasília: Ministério da Saúde, 2000.

BRASIL. Ministério da Saúde. Manual de Controle de Doenças Sexualmente Transmissíveis. Brasília. Coordenação Nacional de DST/AIDS. Brasília: Ministério da Saúde, 1998. 
BRASIL. Ministério da Saúde. Manual de Controle de Doenças Sexualmente Transmissíveis. Brasília. Coordenação Nacional de DST/AIDS. Brasília: Ministério da Saúde, 1999.

BRASIL. MINISTÉRIO DA SAÚDE. Secretaria de políticas de saúde e coordenação de DST/AIDS. Vigilância do HIV no Brasil - novas diretrizes. Brasília: Ministério da Saúde, 2002.

BRETON, Philippe. A Argumentação na comunicação. Bauru: EDUSC, 2003.

BUSS, Paulo. M. Uma introdução ao conceito de promoção da saúde. In: CZERESNIA, Dina; MACHADO, Carlos de Freitas (orgs) . Promoção da Saúde: conceitos, reflexões, tendência. Rio de Janeiro: Fiocruz, 2003.

BUSS, Paulo. M.; RAMOS, C.L. Desenvolvimento local e Agenda 21: desafios da cidadania. Cadernos da oficina social. n. 3, 2000. p. 13-65.Ago. 2005.

EPSTEIN, Isaac [et al.]. Mídia e Saúde. Adamantina: UNESCO/UMESP/FAI, 2001.

FOUCALT, Michel. Sexo, poder e a política da identidade. Entrevista com B. Gallagher e A. Wilson em junho de 1982. The Advocate, n. 400, 7 de agosto de 1984. Tradução de Wanderson Flor do Nascimento. Disponível em: http://vsites.unb.br/fe/tef/filoesco/foucault/sexo.pdf. Acesso em: 16 de abril de 2011.

GIAMI, Alain [et al.]. Enfermeiras frente a Aids: Representações e condutas, permanência e mudanças. Canoas: Ed. ULBRA, 1997.

JOLY, Martine. Introdução à análise da imagem. São Paulo: Papirus, 1996.

LAKOFF, George; JOHNSON, Mark. Metáforas da vida cotidiana. Campinas, SP: mercado de Letras: EDUC, 2002.

MARQUES, Maria Cristina da Costa. A História de Uma Epidemia Moderna. A emergência Política da Aids/HIV no Brasil. Maringá: EDUEM, 2003.

MAZZOTTI, Tarso. A verdade como consenso determinado pelas técnicas argumentativas. GT Pragmatismo Encontro: Verdade: da Metafísica moderna ao pragmatismo. Rio de Janeiro: In: http://homepage.mac.com/tmazzotti/Eloquentia acessado em 23 de novembro de 2007.

MEYER, Michel. Questões de Retórica: Linguagem, Razão e Sedução. Lisboa. Ed.70, 1997 
MINISTÉRIO DA SAÚDE. Notícias AIDS. www.agenciaaids.gov.br. Acesso em: 07 de fevereiro de 2005.

OLIVEIRA, José Marcelo Domingos. A prevenção à Aids e o desafio da ação intersetorial. In: Vulnerabilidade social e Aids: o desafio para a prevenção em tempos de pauperização da epidemia . Org. José Bernardi. Porto alegre, RS: Pastoral de DST/Aids - CNBB, 2005.

OLIVEIRA, Suely Broxado; WEINSTEIN, Charles. AIDS: duas décadas. Epidemia/ Pandemia/Vulnerabilidade Social O que vem depois? . In: BRASIL. MINISTÉRIO DA SAÚDE. Manual de Prevenção do HIV/AIDS para profissionais de Saúde Mental. Ministério da Saúde. Brasília: Ministério da Saúde, 2004. P. 16-23.

PAIVA, Vera. Sem mágicas soluções: a prevenção do HIV e da Aids como um processo de Emancipação Psicossocial. Divulgação em saúde para debate, Rio de Janeiro, n. 27, p. 58-69, agosto de 2003.

PATRINI, Augusto. Para gay: dia de liberdade e de luta. In: http://cellos.blogspot.com, acesso em 19 de janeiro de 2008.

PERELMAN, Chaim; OLBRECHTS-TYTECA, Lucie. Tradado da Argumentação. São Paulo: MARTINS fontes, 2005.

PORTUGAL, Ministério da Saúde. In: www.aidsportugal.com/article.php?sid850 acesso em 27 de setembro de 2007.

RACHID, Márcia. Manual de HIV/Aids. Rio de Janeiro: Editora Revinter, 2000.

REBOUL, Olivier. Introdução a retórica; Tradução Ivone Castilho Benedetti. São Paulo: Martins fontes, 1998.

SACCHI, Luis Henrique dos Santos. Do discurso publicitário biomédico ao discurso publicitário comercial: o marketing social e suspeição nas campanhas de prevenção ao HIV/Aids. GT: educação e comunicação nº 16 ULBRA, 2005.

SANTAELlA, Lucia. Comunicação e Pesquisa. São Paulo: Hacker Editores, 2001.

SARACENI, Valéria. A avaliação de campanhas de saúde com ênfase na sífilis congênita: uma revisão sistemática. Revista brasileira de Saúde e Maternidade Infantil, Recife, 5(3): 263-273, jul./set., 2005. 
SÃO PAULO. Secretaria de Estado da Saúde - 20 Anos - Programa Estadual DST/AIDS SP - Centro de Referência e Treinamento. São Paulo: SESPA, 2004.

SILVEIRA, Jane Rita Caetano da. A Imagem: interpretação e comunicação. Revista linguagem em (Dis)curso, volume 05, número especial, 2005.

Universidade Estácio de Sá, 2005. Comunicação on-line: "Tarso Mazzotti" tmazzotti@mac.

XAVIER, Caco. Aids é coisa séria! - humor e saúde: análise dos cartuns inscritos da I Bienal Internacional do humor. In: Revista História, Ciências, Saúde, vol. VIII, Rio de Janeiro, 1997. 